\title{
POLÍTICA NACIONAL DE RESÍDUOS SÓLIDOS: PERSPECTIVAS DE CUMPRIMENTO DA LEI 12.305/2010 NOS MUNICÍPIOS BRASILEIROS, MUNICÍPIOS PAULISTAS E MUNICÍPIOS DA REGIÃO DO ABC
}

\author{
NATIONAL POLICY OF SOLID WASTE: \\ FULFILLMENTS' PERSPECTIVES OF THE LAW \\ 12.305/2010 BY THE BRAZILIAN MUNICIPALITIES, \\ MUNICIPALITIES OF THE STATE OF SÃO PAULO \\ AND MUNICIPALITIES OF THE ABC REGION
}

\author{
Recebido: 27-02-2014 \\ Aceite: 04-03-2013 \\ Maria Helena Scalabrin Cardoso Gomes ${ }^{1}$ \\ Edenis Cesar Oliveira² \\ Luís Paulo Bresciani ${ }^{3}$ \\ Raquel da Silva Pereira ${ }^{4}$
}

\section{RESUMO}

A Política Nacional de Resíduos Sólidos, instituída pela Lei n.o 12.305/2010, determinou que os municípios brasileiros elaborassem e entregassem seus respectivos Planos de Gerenciamento de Resíduos Sólidos até 2012, impondo a erradicação dos "chamados" lixões até o ano de 2014. A referida lei estabelece responsabilidade compartilhada durante o ciclo de vida do produto (produção, comercialização, consumo e destino das embalagens). O Censo IBGE 2011 e pesquisas posteriores, embora fragmentadas, mostraram uma situação complexa e com baixa probabilidade de cumprimento das exigências no prazo estabelecido. Observa-se no cenário nacional a existência de programas iniciados e interrompidos devido à falta de educação ambiental, à ineficiência das campanhas de conscientização, à dificuldade de aceitação da norma pela comunidade e, tendo sido implantada a coleta seletiva, à falta de locais apropriados para triagem e estocagem. Nesse contexto, este artigo, a partir de uma pesquisa exploratória, bibliográfica e documental, analisou o quadro atual dos municípios brasileiros e, em especial, as políticas adotadas no Estado de São Paulo, com destaque para três municípios da região do Grande ABC. Constatou-se, a partir dos dados apresentados, uma grande distância a ser percorrida para o atendimento dos principais quesitos da Política Nacional de Resíduos Sólidos.

Palavras-chave: Gestão de Resíduos Sólidos. Meio Ambiente. Sustentabilidade.

1 Possui graduação em Administração pela Pontifícia Universidade Católica de São Paulo - PUCSP. Mestrado em Educação, Administração e Comunicação pela Universidade São Marcos - UNIMARCO. Atualmente é doutoranda em Administração pela Universidade Municipal de São Caetano do Sul - USCS. São Caetano, São Paulo. Brasil. Email: mhscgomes@gmail.com

2 Possui graduação em Administração de Empresas pelo Centro Universitário Euripedes de Marília - UNIVEM. Mestrado em Geografia Humana pela Faculdade de Ciências e Tecnologia - UNESP. Atualmente é doutorando em Administração pela Universidade de São Caetano do Sul - USCS. Paraguaçú Paulista, São Paulo. Brasil. Email: edenis@netonne.com.br

3 Possui graduação e mestrado em Engenharia da Produção pela Universidade de São Paulo - USP. Doutorado em Política Científica e Tecnológica pela Universidade Estadual de Campinas - UNICAMP. Atualmente é professor em Administração na Universidade Municipal de São Caetano do Sul - USCS. São Caetano do Sul, São Paulo. Brasil. Email: Ipbresciani@uscs.edu.br.

4 Possui graduação em Administração pela Universidade São Judas Tadeu. Mestrado em Administração pela Pontifícia Universidade Católica de São Paulo - PUCSP. Doutorado em Ciências Sociais pela Pontifícia Universidade de São Paulo - PUCSP. Atualmente é professora na Universidade Municipal de São Caetano do Sul - USCS. São Caetano do Sul, São Paulo. Brasil. Email: raquelspereira@ uscs.edu.br. 


\section{ABSTRACT}

The National Policy of Solid Waste, established by Law No. 12.305/2010, determined that, municipalities should draw up and submitted their Plans until 2012, demanding the eradication of "called" landfills by the year 2014. The law establishes the co-responsibility during the life cycle of the product, from its production/consumption till the final packages' destination. The IBGE Census 2011, and subsequent researches, although fragmented, showed a complex situation with low probability to accomplish it till the established deadline. It is possible to observed in the national scenario that some programs have been started and interrupted due to lack of environmental education or awareness campaigns' inefficiency, as well as difficulty of program's acceptance by local community or, even when them have been implemented, a lack of space for collecting and storing appropriately. This study, starting from the exploratory research, literature and documents, analyzes the municipalities' national current situation and, in particular, the policies adopted in the State of São Paulo, bringing also a cutout in three municipalities of the $A B C$ Region. It was found from the data here presented that a long distance needed to be travelled in order to attend the main points covered by the National Policy for Solid Waste.

Keywords: Solid Waste Management. Environment. Sustainability.

\section{INTRODUÇÃO}

A Lei 12.305, promulgada em 02 de agosto de 2010, "dispõe sobre os princípios, objetivos e instrumentos, bem como as diretrizes relativas à gestão integrada e ao gerenciamento dos resíduos sólidos", estabelecendo a Política Nacional de Resíduos Sólidos (PNRS, 2010), que é uma proposta atual, abrangente e complexa, composta por 57 artigos. Nesse contexto, o presente estudo analisa a responsabilidade atribuída ao estado e à municipalidade pelo destino final dos resíduos.

A esse respeito, ressalta-se o alerta de Malthus, em An Essay on the Principle of Population, obra publicada em 1798, sobre projeções do crescimento populacional e da pobreza, em virtude da incapacidade de se extraírem insumos à vida humana pelos recursos naturais por um longo prazo. Em seus cálculos, o crescimento populacional avançava em escala geométrica, enquanto que a produção de alimentos aumentava em escala aritmética. Sua advertência foi vista com alguma descrença pelos estudiosos de seu tempo (MALTHUS, 1976; ABBAGNANO, 2000; HUISMAN, 2002).

Revisitando Malthus, observa-se que, embora não houvesse aceitação unânime de suas proposições, o economista inglês vislumbrou pontos importantes relativos ao estrangulamento da cadeia alimentar na manutenção da vida humana. Parte do problema - escassez de alimento e crescimento populacional - foi minimizada pelos avanços tecnológicos, mas à custa da exagerada exploração de recursos naturais e devastação do meio ambiente. Um ponto de acerto nas projeções do economista foi a demanda consumista em excesso das populações mais abastadas, o que levaria ao esbanjamento. $\mathrm{O}$ que lhe faltou - e isso não seria possível prever no final do século XVIII - foi compreender o fato de que tanto essa demanda quanto o esbanjamento se estenderiam às demais classes sociais. O problema agravou-se de tal modo que o que era apenas uma conjectura se transformou em um tema de constante preocupação mundial a partir dos anos 1960 (FISHER, 2011).

O descarte dos resíduos sólidos é um dos extremos de uma extensa cadeia, que começa com a exploração dos recursos naturais, passa pela indústria de transformação e termina na manufatura de bens de consumo. Esse processo é estimulado por um sistema sofisticado de marketing e propaganda para garantir a permanência e o crescimento do sistema produtivo. 0 descarte, ponto último dessa sequência, não é mero acidente, mas é previsto desde seu início, uma vez que a obsolescência dos produtos é estrategicamente programada pela indústria.

Diante dessa problemática, ressalta-se o fato de que os lixões têm prazo de término, previsto em lei para o ano de 2014. Entretanto, antes de abordar diretamente o problema em seus aspectos legais, cabe retomar a questão malthusiana não em sua concepção básica, mas 
naquilo que ela menciona como excesso de consumo e esbanjamento. O primeiro tema a ser tratado, portanto, é o consumismo e a degradação do meio ambiente, ponto de partida do aumento dos resíduos sólidos. Autores como Daly (1999), Polzin (2001), Branco (2002) e Brown (2002) examinam o modelo econômico atual, avaliando o impacto do crescimento das cidades, o consumo e o descarte e a degradação ambiental daí decorrente.

A relação entre meio ambiente e sustentabilidade; a banalização deste último termo, antes mesmo que passasse eficientemente do conceito à realidade; as implicações políticas do problema; a dissociação entre melhoria da qualidade de vida e consumo ou entre felicidade e determinados padrões consumistas, tais como compreendidos modernamente, são questões observadas na consulta à Baudrillard (2000), Portilho (2005), Milaré (2007) e mesmo à Agenda 21.

As questões legais vinculadas ao tema decorrem do exame da Agenda 21, documento de abrangência internacional, proposto na Rio 92, quando cada país delimitou propostas de ações em prol da sustentabilidade socioambiental. O Brasil já acolhera tal princípio no artigo 225 de sua Constituição Federal, o qual estabelece, como direito de todos, um meio ambiente ecologicamente equilibrado e delega o tratamento dos resíduos aos municípios.

Contudo, há certo atraso por parte dos municípios brasileiros quanto ao acatamento dessa lei, quer por falta de recursos financeiros, quer por desconhecimento dos seus benefícios, conforme pode ser observado no decorrer deste estudo. Para o ano de 2013, os estados e municípios deveriam apresentar os projetos integrados determinados pela PNRS e, para 2014, estava prevista a conclusão total desses planos, o que não ocorreu.

Desse modo, esta pesquisa objetiva realizar um levantamento da situação dos municípios brasileiros, nos âmbitos nacional, estadual e regional. As fontes relativas ao assunto se apresentam ora em forma fragmentária, ora sem ordem cronológica comum, e com informações dispostas de maneira desigual. Os dados oficiais necessários foram encontrados apenas no Instituto Brasileiro de Geografia e Estatística (IBGE), censo 2011, sob a denominação de Perfil dos Municípios Brasileiros, documento elaborado pela Diretoria de Pesquisas, Coordenação de População e Indicadores Sociais. Essa escolha do censo do IBGE como fonte de dados também se justifica por captar o momento da gestão municipal brasileira relativa à destinação dos resíduos sólidos municipais, logo após a promulgação da lei.

Assim, este trabalho se propôs a analisar, a partir de dados divulgados pelo IBGE/MUNIC (2011), o quadro geral dos municípios brasileiros no tocante à sua gestão dos resíduos sólidos, especialmente a partir da promulgação da PNRS, de acordo com a Lei 12.305, de 02 de agosto de 2010. No âmbito estadual, verificou-se a situação dos municípios paulistas, a partir do Inventário Estadual de Resíduos Sólidos Urbanos (SECRETARIA DO MEIO AMBIENTE/CETESB/2012), e em particular do $A B C$.

\section{REVISÃO TEÓRICA}

Em seus distintos extratos, os aglomerados populacionais têm algo em comum: o consumismo, dirigido pelo modelo econômico e pelos valores culturais vigentes, geradores de necessidades simbólicas (BRANCO, 2002). O lixo associado à degradação ambiental já ocorria no final do século XVIII, fenômeno decorrente da Revolução Industrial. Entretanto, como a população naquela época era muito menor do que a atual, esse impacto passou despercebido. Dessa forma, o círculo que se estabeleceu - entre o crescimento populacional, industrial e urbano e o aumento do consumo, do descarte e da poluição - foi difícil de ser previsto em toda a sua dimensão no século XVIII, pois o consumo era parcialmente restrito e boa parte dos resíduos produzidos era de fácil degradação. 
A partir de então, o volume de resíduos produzidos nas cidades manifesta a evolução da economia mundial do descarte, que precisa ser substituída pela economia da redução, da reutilização e da reciclagem (BROWN, 2002). Desde a atividade biológica até a ação antrópica, a produção descontrolada de rejeitos é constante (POLZIN, 2001), o que não ocorre nos ecossistemas, em que os rejeitos de um organismo são os alimentos de outros, em uma cadeia perfeita.

A capacidade do meio ambiente equilibrado de suprir a cadeia da vida é proporcionalmente inversa à capacidade de absorção dos resíduos decorrentes da ação antrópica. Nesse cenário, a economia aparece como um subsistema do meio ambiente, fonte de matérias-primas ou de depósito de resíduos (DALY, 1999).

Lélé (1991) chama a atenção para as contradições e trivialidades sobre os debates em torno da sustentabilidade do ecossistema: ocorre o desenvolvimento da sustentabilidade ou ocorre a sustentabilidade do desenvolvimento? Além de criticar a banalização do jargão "desenvolvimento sustentável", o autor enfatiza a percepção parcial da miríade dos problemas acarretados pela pobreza e pela degradação ambiental. O que acontece, na verdade, é uma confusão entre o papel do crescimento da economia e os conceitos de sustentabilidade da vida.

Não obstante, Lélé (1991) comenta os dilemas das agendas públicas no tratamento do problema: a necessidade de adotar uma posição firme sobre o assunto ou ganhar a aceitação política mais ampla. Essa questão decorre da falta de uma compreensão maior sobre o assunto, da falta de firmeza na condução dos negócios públicos e da aceitação política. São fatos que não divergem entre si, mas, se analisados sob uma abordagem correta, trariam maior flexibilidade e diversidade na formulação de estratégias mais condizentes com a sustentabilidade ecológica e social.

Diante disso, surge a seguinte questão: "como fazer essa relação entre população e impacto ambiental sem resgatar o paradigma malthusiano?" (HOGAN et al., 2010, p. 39). Como resposta, os pesquisadores apontam a necessidade de conhecer a relação população-consumo para avaliar o impacto que cada pessoa exerce no meio ambiente.

Os estudos acerca dos impactos dos resíduos sólidos decorrentes do consumismo são vastos, mas a apreensão desse conceito ainda está em fase de maturação econômica e social. Trata-se de um fenômeno complexo, uma vez que o modelo econômico se assenta em níveis cada vez mais elevados de consumo e, consequentemente, de descartes. Assim, o primeiro passo de uma atitude pró-ambiente é atribuir à cadeia produtiva a responsabilidade pelo recolhimento dos resíduos gerados por seus produtos, o que se denomina de responsabilidade pós-consumo. Quando se leva em conta as medidas efetivas que os governos tomaram para tratar a questão, o documento mais abrangente é a Agenda 21, que destaca em seu capítulo 4:

A pobreza e a degradação do meio ambiente estão estritamente relacionadas. Enquanto a pobreza tem como resultado determinados tipos de pressão ambiental, as principais causas da deterioração ininterrupta do meio ambiente mundial são os padrões insustentáveis de consumo e produção, especialmente dos países industrializados. Motivo de séria preocupação, tais padrões de consumo provocam o agravamento da pobreza e dos desequilíbrios (BRASIL. AGENDA 21, 1995, p. 33).

O equívoco de que a melhoria da qualidade de vida está associada ao ato de consumir é a base do desenvolvimento econômico. As necessidades humanas, na ótica da sociedade de consumo, são ilimitadas, enquanto que os recursos naturais são restritos. Sobre o assunto, Baudrillard afirma que todo discurso sobre as necessidades se assenta em uma antropologia ingênua: a propensão natural para a felicidade. A felicidade constitui, assim, a referência absoluta da sociedade de consumo, revelando-se como o equivalente autêntico da salvação (2000, p. 47). Na Agenda 21 e nas observações de Baudrillard, observa-se que um novo paradigma precisa ser instalado, abandonan- 
do a régua de medição de desempenho das empresas de sucesso que está fundamentada na cartiIha que associa o máximo consumo (produção e vendas) à percepção de felicidade e ao bem-estar.

As raízes da crise ambiental assentam-se nos atuais padrões de consumo: uso excessivo dos recursos naturais e, consequentemente, aumento do descarte. Uma política de sustentabilidade pressupõe a transformação na estrutura e nos padrões definidores de produção e consumo, colocando em primeiro plano a capacidade de sustentação e o impacto no equilíbrio ambiental (PORTILHO, 2005).

Nesse contexto, a PNRS reconhece o princípio do poluidor-pagador, introduzido pela Organização para a Cooperação e Desenvolvimento Econômico (OCDE), responsável pelos fundamentos dos aspectos econômicos das políticas ambientais. Impõe às pessoas naturais ou jurídicas, regidas pelo direito público ou privado, o pagamento dos custos das medidas destinadas a eliminar a contaminação provocada ou a redução desta ao limite fixado pelos padrões que asseguram a qualidade de vida (ANTUNES, 2010).

Esse princípio surgiu no ordenamento jurídico brasileiro em 1981, por meio da Lei 6.938 (Política Nacional de Meio Ambiente, artigo 4, inciso VII), e posteriormente foi ratificado pela Constituição Federal de 1988, estabelecendo a tutela ambiental e consagrando nova dimensão para o Estado Democrático de Direito, o qual deve estar submetido aos princípios ecológicos. Também estabelece como direito de todos um "meio ambiente ecologicamente equilibrado" e impõe aos governos a obrigatoriedade da execução de políticas voltadas para esse fim.

O artigo 30, da Constituição Federal de 1988, estabelece como sendo de competência do município: "I - legislar sobre assuntos de interesse local; [...] V - organizar e prestar, diretamente ou sob regime de concessão ou permissão, os serviços públicos de interesse local, incluído o de transporte coletivo, que tem caráter essencial; [...] VIII - promover, no que couber, adequado ordenamento territorial, mediante planejamento e controle do uso, do parcelamento e da ocupação do solo urbano" (BRASIL, CF/88).

Diante disso, ressalta-se que a limpeza urbana, compreendida como logística de gestão dos resíduos sólidos (coleta, transporte, acondicionamento e destinação final), figura como um serviço que se enquadra nas determinações constitucionais. Compete ao município organizar e prestar os serviços públicos de interesse local, como coleta e destino adequado de todo lixo gerado.

Quanto aos indicadores que compõem o Barômetro da Sustentabilidade (AGENDA 21), é recomendável considerá-los em conjunto. Porém, devido ao limite do presente estudo, fez-se necessário um recorte, de modo que os indicadores foram tomados separadamente, mesmo correndo-se o risco de que a análise reduzisse a dimensão do problema.

\section{POLÍTICA NACIONAL DE RESÍDUOS SÓLIDOS}

A gestão dos resíduos sólidos constitui-se em um problema emergente da sociedade moderna. As ações antrópicas, qualquer que seja sua ordem, via de regra, produzem algum tipo de resíduo. Como agravante, pode-se citar o fato de que o acúmulo contínuo dos resíduos sólidos no decorrer do tempo aumenta seu volume e que a forma de disposição final desses resíduos é inadequada.

Atualmente, mais de $80 \%$ da população mundial reside em cidades. As projeções indicam que em 2050 o número de pessoas vivendo em ambientes urbanos será extremamente elevado, o que tornará ainda mais complexos os desafios relativos à disposição dos resíduos. Para Mavropoulos (2010), grande parte do aumento populacional deverá ocorrer nos países em desenvolvimento, de modo que não seria exagero afirmar que os resíduos sólidos podem ser considerados uma questão eminentemente urbana (HOORNWEG e BHADA-TATA, 2012). 
A crescente preocupação com o meio ambiente em geral e com a questão da saúde pública em particular relacionada a resíduos sólidos indica que políticas sociais com a finalidade de tratar desses temas tendem a ser cada vez mais demandadas. Além disso, sabe-se que a mudança para uma sociedade mais sustentável exige, necessariamente, maior sofisticação na gestão dos resíduos (SEADON, 2010). De acordo com esta perspectiva, a gestão dos resíduos nas cidades assume escala de um desafio social e ambiental (EZEAH e ROBERTS, 2012).

Com vistas a atender a essas demandas, a Política Nacional de Resíduos Sólidos (PNRS) reuniu um conjunto de princípios, diretrizes, objetivos, instrumentos, metas e ações a serem adotadas pela União, isoladamente ou em parceria com os estados, o Distrito Federal, os municípios e os entes privados. Seu objetivo foi construir uma gestão integrada dos resíduos sólidos, ambientalmente adequada.

O conteúdo da referida lei considera essas práticas relacionadas com a gestão dos resíduos sólidos: sua não geração; sua redução; sua separação das frações e seu processamento em usinas de reciclagem; a adoção de ações para recuperar a energia neles contida; e, quando a reciclagem não for possível, seu tratamento e sua disposição com tecnologia e com custos acessíveis. A PNRS traz alguns conceitos que até então careciam de uma definição mais clara, como, por exemplo, sustentabilidade operacional e financeira, logística reversa, acordo setorial, integração de catadores, padrões sustentáveis de produção e consumo. Com isso, a PNRS visa, entre outros aspectos, à proteção da saúde pública e da qualidade ambiental e à disposição final ambientalmente adequada. $\mathrm{O}$ artigo 3 o da PNRS define resíduos sólidos como:

XVI - resíduos sólidos: material, substância, objeto ou bem descartado resultante de atividades humanas em sociedade, a cuja destinação final se procede, se propõe proceder ou se está obrigado a proceder, nos estados sólido ou semi sólido, bem como gases contidos em recipientes e líquidos cujas particularidades tornem inviável o seu lançamento na rede pública de esgotos ou em corpos d'água, ou exijam para isso soluções técnica ou economicamente inviáveis em face da melhor tecnologia disponível (BRASIL, Lei no 12.305/10, inciso XVI, art. 3ㅇ).

Considerada um marco histórico na gestão ambiental do Brasil, a PNRS apresenta uma visão moderna no combate a um dos maiores problemas do planeta: o lixo urbano. Tendo como um dos princípios a responsabilidade compartilhada entre governo, empresas e população, a nova legislação impulsiona o retorno dos materiais descartados às indústrias após o consumo, por meio da logística reversa, além de obrigar o poder público municipal a elaborar, implementar e executar planos para o gerenciamento desses resíduos.

A PNRS define três requisitos básicos a serem abordados: 1) a elaboração de planos de tratamento de resíduos sólidos; 2) o princípio de responsabilidade compartilhada pelo ciclo de vida dos produtos entre governo, empresas e consumidores; e 3) a participação dos catadores de recicláveis e de materiais reutilizáveis no sistema de logística reversa. Assim, a lei possui duas grandes dimensões de abrangência: a gestão dos resíduos industriais, que deverá ser articulada entre as câmaras setoriais, por meio de regulamentações específicas, e a gestão municipal de resíduos sólidos, com a elaboração dos planos integrados para o seu gerenciamento - dimensão analisada por esta pesquisa.

Ressalta-se que compete aos municípios a gestão dos resíduos sólidos neles gerados. Assim, a PNRS determina o estabelecimento de planos de gestão desses resíduos pelo município, por meio do Plano Municipal de Gestão Integrada de Resíduos Sólidos (PMGIRS) - nos quais deverá estar contemplado o conteúdo mínimo descrito na PNRS. As providências tomadas pelos municípios devem fazer parte do conceito de gerenciamento integrado dos resíduos, o que en- 
volve diferentes abordagens e soluções, incluindo desde a reciclagem até a disposição dos rejeitos em aterros sanitários, sempre de acordo com os critérios legais.

A Agência Americana de Proteção Ambiental (EPA) define Gestão Integrada de Resíduos Sólidos (GIRS) como um programa abrangente de prevenção, reciclagem, compostagem e eliminação de resíduos. Um sistema eficaz de GIRS indica como evitar, reciclar e gerenciar os resíduos de forma a proteger a saúde humana e o meio ambiente. A GIRS deve observar as necessidades e condições locais para, em seguida, selecionar e combinar as atividades de gestão mais adequadas e aplicáveis (EPA, 2002).

A gestão de resíduos é fundamental na agenda da administração do município, inclusive para preservar a saúde pública. Além disso, o setor absorve parte considerável dos recursos do orçamento do município, sendo, ainda, um importante fornecedor de emprego no setor público (KLUNDERT e ANSCHÜTZ, 2001). O Banco Mundial estima que, em países em desenvolvimento: de $20 \%$ a $50 \%$ dos orçamentos municipais sejam utilizados no gerenciamento de resíduos sólidos; entre $30 \%$ e $50 \%$ dos resíduos sólidos urbanos não sejam coletados; e menos de $50 \%$ da população seja favorecida (UNEP, 2009).

Figura 1: Linha do tempo com os principais marcos legais

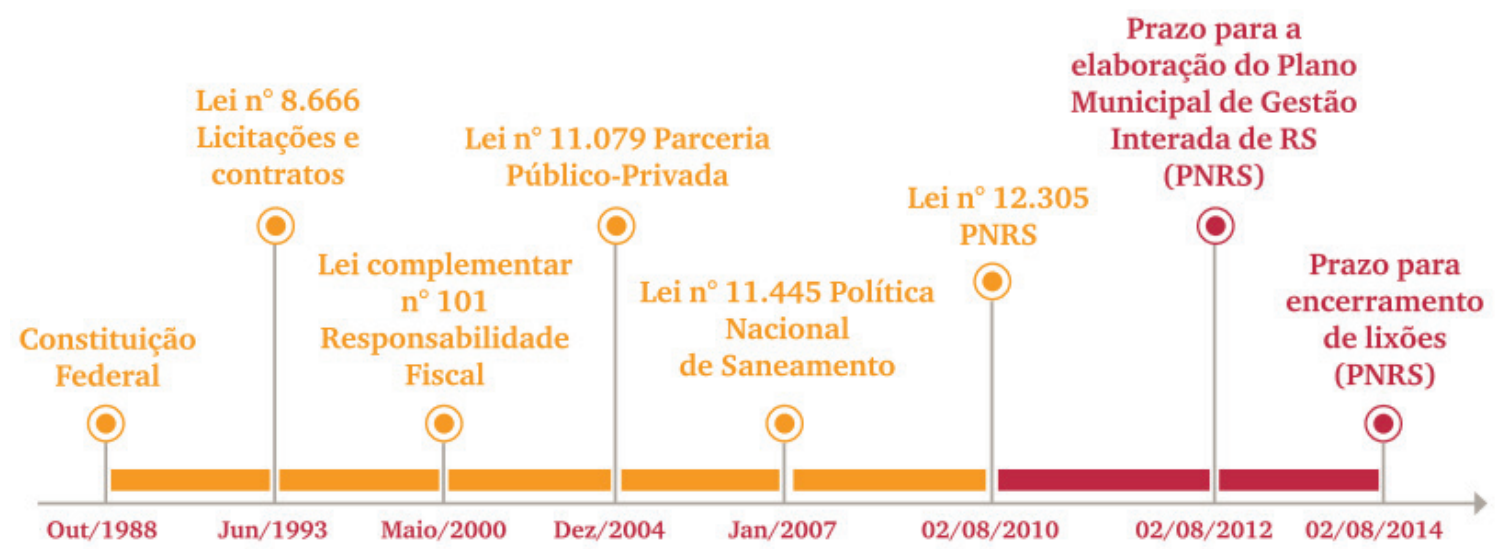

Fonte: PwC Brasil; Selur; ABPL (2011).

Pela nova lei, os governos municipais deveriam ter elaborado o Plano de Gerenciamento de Resíduos Sólidos até 02 de agosto de 2012, o que não ocorreu. Esse instrumento deve ser compatível com a realidade local, contendo um diagnóstico acerca da situação dos resíduos, as metas para redução e para reciclagem e o estabelecimento do fim dos lixões a céu aberto, bem como a busca de soluções consorciadas com outros municípios.

\section{PANORAMA GERAL SOBRE A GESTÃO DE RSU NO BRASIL}

Esta seção apresenta brevemente uma visão geral sobre os Resíduos Sólidos Urbanos (RSU) no Brasil, sobretudo dos anos 2010 e 2011. A Figura 2 apresenta informações relativas à geração de RSU no Brasil (t/ano) e per capita (kg/hab./ano) desse período. 
Figura 2: Geração geral e per capita de RSU no Brasil para os anos de 2010 e 2011

Geração de RSU

(t/ano)
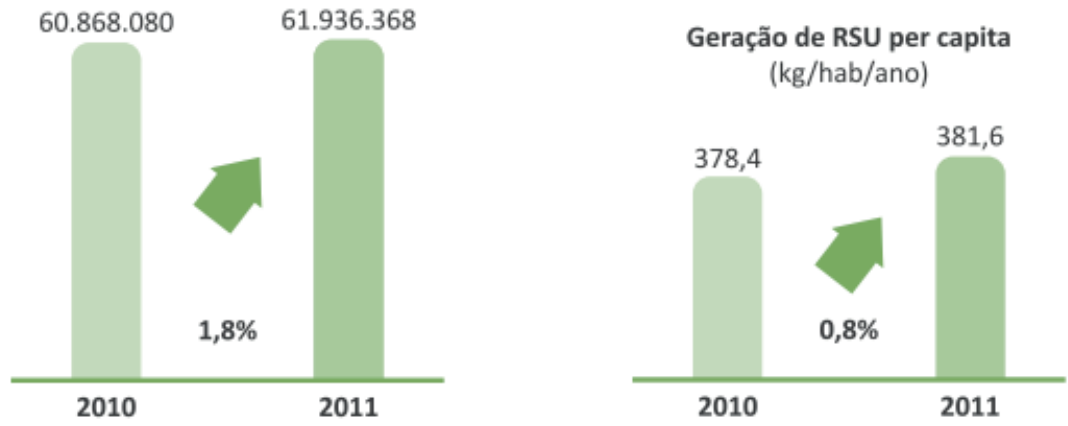

Fonte: ABRELPE, 2013.

A geração de resíduos sólidos é o indicador mais importante para dimensionar a escala que terão os diferentes serviços de sua gestão, além de prever as dificuldades a serem encontradas nos processos. Serve, assim, como parâmetro para a tomada de decisões no que se refere ao planejamento dos sistemas de coleta e disposição final (ESPINOZA et. al., 2011).

Conforme os dados, pode-se observar o aumento de $1,8 \%$ na quantidade de resíduos gerados do ano de 2010 para o ano de 2011, representando mais de um milhão de toneladas, o que pode ser bastante significativo tendo em vista o curto prazo de um ano. A Figura 3 mostra dados relacionados com a coleta geral e per capita de RSU no Brasil para os anos de 2010 e 2011.

Figura 3: Coleta global e per capita de RSU no Brasil para os anos de 2010 e 2011

coleta de RSU

(t/ano)
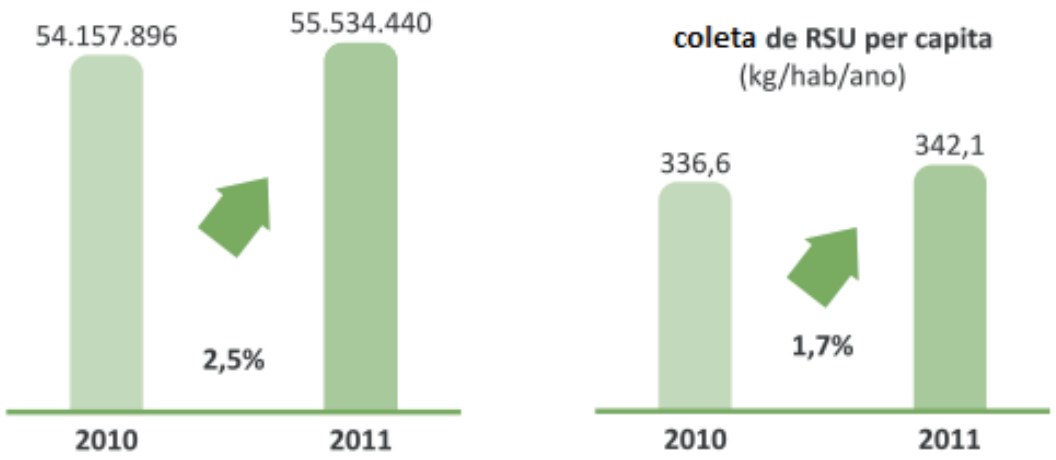

Fonte: Adaptado de ABRELPE, 2013.

Observa-se um importante aumento na coleta de resíduos do ano de 2010 para o ano de 2011, com percentual mais elevado que o da geração de resíduos (Figura 2). Todavia, não se pode omitir que mais de seis milhões de toneladas de resíduos deixaram de ser coletados no período. Seria exagero postular que, talvez, parte ou todo desse volume não coletado regularmente estaria abastecendo os lixões a céu aberto ainda existentes no país?

A Figura 4 apresenta dados referentes à disposição final de RSU. Observa-se um aumento que ultrapassa a casa de um milhão de toneladas de resíduos dispostos adequadamente do ano 2010 para o ano de 2011. Contudo, o aumento ficou em 0,5 pontos percentuais do total de disposição de resíduos. 
Figura 4: Disposição final de resíduos sólidos coletados no Brasil
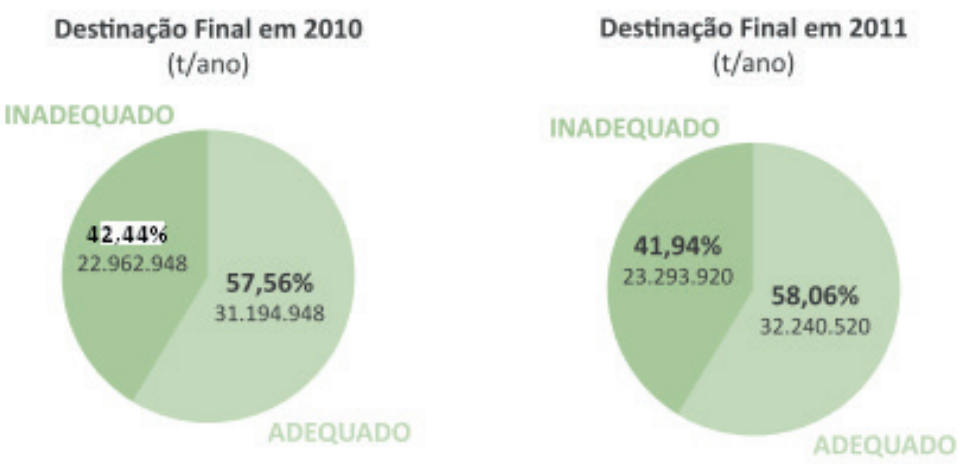

Fonte: Adaptado de ABRELPE, 2013.

Embora tenha havido uma pequena redução percentual no volume de resíduos sólidos inadequadamente dispostos, na ordem de 0,5 pontos percentuais, o volume, em toneladas, aumentou em mais de 330.000 no período. Destaca-se, diante disso, a necessidade de ações imediatas em virtude dos seguintes fatos: 1 ) apesar do progresso alcançado com relação à disposição adequada de RSU, fica evidente que ainda há muito a ser feito para eliminar a ameaça sanitária e ambiental dos lixões a céu aberto e que a disposição em geral é inadequada; 2) considerando que, no ano de 2011, 6,4 milhões de toneladas de resíduos deixaram de ser recolhidas, percebese a necessidade de aprimoramento do sistema de coleta. A coleta seletiva e reciclagem são elementos básicos e indispensáveis de todo sistema de gerenciamento de resíduos sólidos: a coleta é considerada pela PNRS um dos instrumentos (artigo 8oㅡ., inciso III), ao passo que a reciclagem constitui-se em um dos objetivos da referida lei (artigo 70, inciso II).

De acordo com dados do IBGE/MUNIC, em 2011, dos 5.565 municípios brasileiros, somente 854 informaram a existência de iniciativas de coleta seletiva. A Tabela 1 mostra a quantidade de municípios por região e no Brasil que adotaram tal prática.

Tabela 1: Municípios com programa ou projeto ou ação de coleta seletiva de lixo por região e no Brasil em 2011

\begin{tabular}{cccc}
\hline Regiões & $\begin{array}{c}\text { Número Total } \\
\text { de Municípios }\end{array}$ & $\begin{array}{c}\text { Municípios com Iniciativa } \\
\text { de Coleta Seletiva }\end{array}$ & $\begin{array}{c}\text { \% de Municípios com } \\
\text { Iniciativa de Coleta Seletiva }\end{array}$ \\
\hline BRASIL & 5565 & 854 & 15,35 \\
Norte & 449 & 23 & 0,41 \\
Nordeste & 1794 & 107 & 1,92 \\
Centro-Oeste & 466 & 32 & 0,57 \\
Sudeste & 1668 & 348 & 6,25 \\
Sul & 1188 & 344 & 6,18 \\
\hline
\end{tabular}

Fonte: IBGE/MUNIC, 2011.

Os dados da Tabela 1 evidenciam o quanto ainda existe para ser feito com respeito às iniciativas de coleta seletiva nos municípios. Pouco mais de $15 \%$ dos municípios brasileiros possuem algum tipo de ação nesse sentido. Em termos percentuais, a região Norte é a que apresenta menor quantidade de iniciativas de coleta seletiva, ao passo que as regiões Sudeste e Sul lideram o ranking, com um patamar pouco superior a $6 \%$. A PNRS, por meio de seus instrumentos e objetivos, estimula a adoção de medidas de gestão que redundem em práticas efetivas no intuito de avançar na ampliação desse importante aspecto. 


\section{PROCEDIMENTOS METODOLÓGICOS}

A metodologia adotada neste estudo foi a pesquisa exploratória, por proporcionar maior familiaridade com o problema, tornando-o mais explícito (GIL, 2010). Pode ser também classificada como descritiva, uma vez que expõe características de determinada população ou de determinado fenômeno (VERGARA, 2010). As informações foram coletadas e sistematizadas diretamente do banco de dados disponibilizado pelo IBGE/MUNIC/2011; CEMPRE, 2012 e Secretaria do Meio Ambiente do Estado de São Paulo/CETESB/2012. Além disso, pesquisas primárias exploratórias foram realizadas junto às Secretarias de Comunicação e Meio Ambiente dos Municípios do ABC paulista (Santo André, São Bernardo do Campo e São Caetano do Sul).

\section{ANÁLISE E DISCUSSÃO DOS RESULTADOS}

Os municípios brasileiros teriam até 2014 para encerrar a disposição dos seus resíduos em lixões (Figura 1), conforme determina a PNRS. Entretanto, ainda há 2.906 lixões a serem erradicados no Brasil, distribuídos em 2.810 municípios. A Tabela 2 apresenta a questão no Brasil e nas macrorregiões.

Tabela 2: Número de municípios que possuem lixões no Brasil por Grandes Regiões.

\begin{tabular}{ccccc}
\hline \multirow{2}{*}{ País/Região } & \multirow{2}{*}{ No municípios } & População urbana & \multicolumn{2}{c}{ Municípios com presença de lixões } \\
\cline { 4 - 5 } & & 160.008 .433 & Quantidade & \% \\
\hline Brasil & 5565 & 11.133 .820 & 3.810 & 50,5 \\
Norte & 449 & 38.826 .036 & 1598 & 84,6 \\
Nordeste & 1794 & 74.531 .947 & 311 & 89,1 \\
Sudeste & 1668 & 23.355 .240 & 182 & 18,4 \\
Sul & 1188 & 12.161 .390 & 339 & 15,3 \\
Centro-oeste & 466 & & & 72,7 \\
\hline
\end{tabular}

Fonte: IPEA (2012).

Conforme a Tabela 2, metade dos municípios brasileiros deveria adotar medidas para dispor de forma ambientalmente correta seus resíduos até 2014. Nas grandes regiões, há uma situação de maior complexidade, pois três das cinco regiões possuem quantidade expressiva de lixões em seus municípios: Nordeste, Norte e Centro-oeste.

Já a Tabela 3 apresenta os programas e projetos de gestão de resíduos sólidos no Brasil e nas regiões brasileiras. Aproximadamente $26 \%$ dos municípios brasileiros (consideradas a área de abrangência de todo o município e de toda a área urbana) possuem projetos e programas de coleta seletiva, ao passo que, em todo o Brasil, 2.376 municípios, cerca de 43\%, não apresentam nenhuma ação ou projeto de coleta. Em 2012, dentre os 5.565 municípios brasileiros, apenas 766 $(13,76 \%)$ possuíam sistemas de coleta seletiva geridos por prefeituras (CEMPRE, 2012). 
Tabela 3: Regiões brasileiras: programas e projetos de gestão de resíduos sólidos

\begin{tabular}{|c|c|c|c|c|c|c|c|c|c|c|c|c|c|c|c|}
\hline \multirow[b]{2}{*}{ 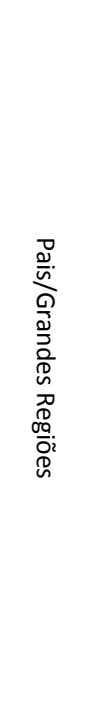 } & \multirow[b]{2}{*}{ 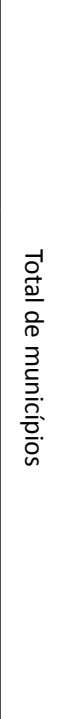 } & \multicolumn{5}{|c|}{$\begin{array}{c}\text { Municípios com programas e } \\
\text { projetos em ATIVIDADE } \\
\text { Abrangência da Coleta }\end{array}$} & \multirow{2}{*}{ 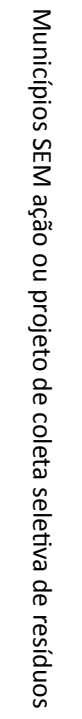 } & \multirow{2}{*}{ 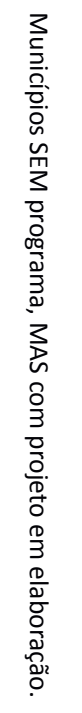 } & \multicolumn{4}{|c|}{$\begin{array}{l}\text { Municípios com programas ou } \\
\text { projetos INTERROMPIDOS pelos } \\
\text { MOTIVOS: }\end{array}$} & \multicolumn{3}{|c|}{$\begin{array}{l}\text { Prefeituras CIENTES da } \\
\text { existência de Cooperati- } \\
\text { vas/Associações de Ca- } \\
\text { tadores Mat. Recicláveis }\end{array}$} \\
\hline & & 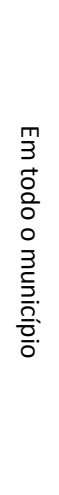 & 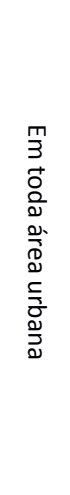 & 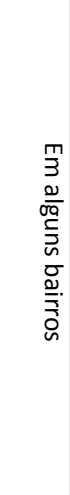 & 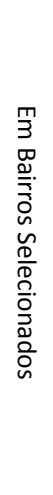 & 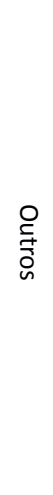 & & & 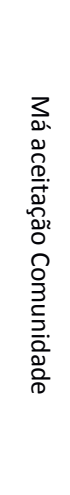 & 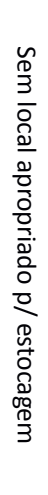 & 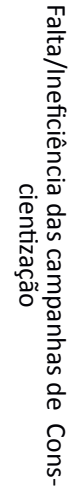 & 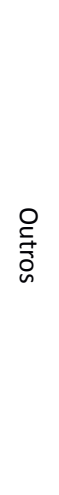 & 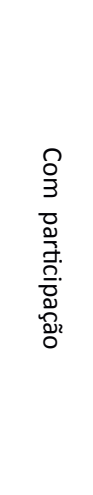 & 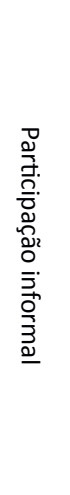 & 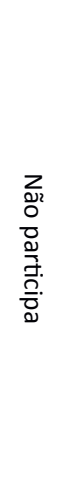 \\
\hline BRASIL & 5565 & 612 & 823 & 162 & 125 & 74 & 2376 & 1070 & 15 & 55 & 25 & 43 & 824 & 620 & 197 \\
\hline NO & 449 & 12 & 37 & 5 & 8 & 3 & 282 & 355 & 0 & 2 & 3 & 2 & 29 & 39 & 18 \\
\hline NE & & 51 & & 32 & 17 & 20 & & & 1 & 7 & 1 & 8 & & & 76 \\
\hline SE & 1668 & 226 & 294 & 92 & 53 & 28 & 528 & 79 & 7 & 12 & 9 & 18 & 390 & 234 & 54 \\
\hline SUL & 1188 & 302 & 283 & 27 & 34 & 17 & 252 & 191 & 6 & 26 & 7 & 9 & 270 & 140 & 34 \\
\hline CO & 466 & 21 & 64 & 6 & 13 & 6 & 196 & 128 & 1 & 8 & 3 & 6 & 43 & 63 & 15 \\
\hline
\end{tabular}

Fonte: Tabela elaborada pelos autores a partir de IBGE/MUNIC (2011).

Em termos percentuais, a região brasileira que se destaca é a região Sul, com 49,24\% de municípios com projetos e programas de coleta seletiva, seguida da região Sudeste, com $31,17 \%$. Vale ressaltar que foi utilizado o mesmo critério para calcular a porcentagem dos dados do país. A coleta seletiva é considerada na nova política de resíduos (PNRS) como um dos instrumentos (artigo 8으, inciso III) e dos elementos básicos e indispensáveis de todo sistema de gerenciamento de resíduos sólidos. Há um longo caminho a ser percorrido no sentido de implementar programas e projetos que levem a ações efetivas de ampliação da coleta, condição necessária para realização da reciclagem, um dos importantes objetivos previstos na PNRS (artigo 70, inciso II).

Apesar do baixo índice de programas ou projetos municipais de coleta seletiva, alguns municípios tiveram ações interrompidas por má aceitação da comunidade. O segundo motivo mais apontado para isso é a falta de local apropriado para a triagem, seguido da ineficiência das campanhas públicas. Esses fatos impedem avanços importantes nessa questão.

As campanhas de conscientização precisam ser revistas, entendidas e implementadas como uma importante estratégia de planejamento, sem a qual os esforços seguintes podem não apresentar os resultados almejados. Como início de todo processo, está a formação, a organização e o funcionamento dos Conselhos Municipais de Meio Ambiente, espaço que aglutina representantes das várias instâncias de poder, além da participação da sociedade civil organizada.

A elaboração de um plano de gestão participativa possibilita a construção de políticas de duração mais longa, com grande alcance social. Todavia, menos de 35\% dos municípios brasileiros possuem Conselhos de Meio Ambiente. A Tabela 4 apresenta um panorama por regiões com Conselhos de Meio Ambiente formalizados e em funcionamento. 
Tabela 4: Municípios com Conselhos de Meio Ambiente

\begin{tabular}{cccc}
\hline País/Regiões & Total de Municípios & \multicolumn{2}{c}{ Municípios com Conselhos } \\
\cline { 3 - 4 } & & Quantidade & Percentual \\
\hline Brasil & 5565 & 1917 & 34,45 \\
Norte & 449 & 125 & 27,84 \\
Nordeste & 1794 & 420 & 23,41 \\
Sudeste & 1668 & 684 & 41,00 \\
Sul & 1188 & 532 & 44,78 \\
Centro-oeste & 466 & 156 & 33,48 \\
\hline
\end{tabular}

Fonte: IBGE/MUNIC (2011). Tabela elaborada pelos autores.

Embora o percentual de municípios que contêm Conselhos de Meio Ambiente no Brasil possa ser considerado baixo, observa-se que três regiões brasileiras (Norte, Nordeste e Centro-oeste) apresentam valores ainda menores que o aferido para todo o território nacional. Importa retomar, então, a assertiva de Lélé (1991) quanto à necessidade do poder público tomar uma posição firme sobre o assunto. Há, de fato, um dilema na agenda pública nessa questão.

Conforme disposto na Lei 12.305/2010, o Estado de São Paulo passou a monitorar a eficácia das políticas públicas no atendimento da legislação por meio do Índice de Qualidade dos Resíduos Sólidos (IQR), que permite aferir o resultado das ações de controle da poluição ambiental. No ano de 2011, 492 municípios paulistas $(65,4 \%)$ de um total de 645 estavam operando em situações adequadas, segundo informações da CETESB.

No ano de 2012, especificamente no mês de fevereiro, foi emitido o Decreto Estadual 57.817 e a Resolução 38, que instituíram o Projeto de Implementação de Resíduos Sólidos, em apoio à gestão municipal. No mesmo ano, houve uma significativa evolução, passando para 590 municípios com operações consideradas adequadas e 54 inadequadas $(8,4 \%)$.

Tabela 5: Municípios paulistas em condições consideradas inadequadas.

\begin{tabular}{cccccc}
\hline Município & IQR 2011 & IQR 2012 & Município & IQR 2011 IQR 2012 \\
\hline Apiaí & 7,5 & 5,6 & Miguelópolis & 2,9 & 2,7 \\
Arandu & 3,4 & 2,2 & Mirandópolis & 6,5 & 4,5 \\
Auriflama & 5,1 & 5,5 & Mirante do Paranapanema & 6,8 & 6,7 \\
Bananal & 3,5 & - & Nova Aliança & 3,8 & 2,6 \\
Barra Bonita & 3,7 & 4,0 & Osvaldo Cruz & 5,2 & 4,2 \\
Bauru & 5,9 & 3,0 & Paraguaçu Paulista & 5,1 & 4,8 \\
Bernardino de Campos & 4,3 & 5,4 & Paulo de Faria & 9,0 & 5,3 \\
Buritama & 3,0 & 3,4 & Pedro de Toledo & 8,2 & 6,9 \\
Cabreúva & 6,2 & 6,2 & Peruíbe & 1,7 & 2,5 \\
Capela do Alto & 7,1 & 4,5 & Piedade & 5,9 & 4,4 \\
Cassia dos Coqueiros & 7,8 & 6,8 & Pirajú & 4,9 & 6,8 \\
Coroados & 6,6 & 3,4 & Pirapozinho & 5,3 & 4,2 \\
Eldorado & 7,6 & 4,2 & Presid. Epitácio & 5,9 & 2,9 \\
Florínea & 5,8 & 6,4 & Presid. Prudente & 3,8 & 2,7 \\
Getulina & 8,2 & 7,0 & Presid. Venceslau & 6,2 & 6,1 \\
Herculândia & 5,3 & 5,7 & Registro & 5,4 & 6,3 \\
Igaraçu do Tietê & 6,0 & 3,8 & Riversul & 7,2 & 4,5 \\
Indiana & 7,0 & 6,2 & Sandovalina & 6,9 & 6,9 \\
Iporanga & 8,6 & 6,3 & S. Sebastião da Grama & 4,5 & 5,3 \\
Itapetininga & 3,1 & 5,7 & Serra Azul & 7,3 & 4,4 \\
Itapeva & 6,4 & 5,6 & Santa Mercedes & 6,9 & 6,7 \\
Itapirapuã Paulista & 6,2 & 4,7 & Tabapuã & 8,0 & 6,3 \\
Itápolis & 5,4 & 6,7 & Taciba & 7,2 & 6,7 \\
Itararé & 4,5 & 5,2 & Tarumã & 6,2 & 6,0 \\
Itariri & 3,6 & 3,6 & Ubarana & 2,9 & 2,6 \\
José Bonifácio & 4,8 & 2,6 & Uchoa & 4,5 \\
Juquiá & 3,2 & 5,5 & Valentim Gentil & 8,4 & 5,0 \\
\hline
\end{tabular}

Fonte: CETESB (2012). Tabela elaborada pelos autores. 
Na Tabela 5, é demonstrada a relação dos municípios cujos IQRs estão inadequados, considerando a variação do ano de 2011 para 2012.

Os municípios de Arandu (2,2), Peruibe $(2,5)$, Ubarama $(2,6)$, José Bonifácio $(2,6)$, Miguelópolis $(2,7)$, Nova Aliança $(2,6)$, Presidente Epitácio $(2,9)$ e Presidente Prudente $(2,7)$ apresentaram IQR abaixo de 3,0, sendo considerados, portanto, os de piores condições. Embora continuem com seus IQRs abaixo do ideal, aproximadamente $26 \%$ dos municípios apresentaram pequena elevação no seu índice do ano de 2011 para 2012, o que pode sinalizar que algumas possíveis ações de melhoria estejam sendo implementadas.

Já os municípios de Cabreúva, Itariri e Sandovalina mantiveram seus respectivos IQRs inalterados, ou seja, não apresentaram variação do ano de 2011 para 2012. O município de Bananal apresenta uma situação atípica: "exporta" seus resíduos para o município de Barra Mansa, no Estado do Rio de Janeiro.

\subsection{Região do ABC: consórcio intermunicipal}

Na região do Grande $A B C$, os municípios estão organizados em consórcio intermunicipal, que reúne 13 municípios e tem por finalidade a articulação e o planejamento de ações para o desenvolvimento regional. Dentre as atribuições do Consórcio também estão as Políticas de Resíduos Sólidos. A última Conferência ocorreu no primeiro semestre de 2013, situação em que foram discutidos os seguintes aspectos:

1. a Política Nacional e sua implementação;

2. de que forma incentivar parcerias entre governo, iniciativa privada e sociedade civil;

3. como superar os desafios para a implementação da gestão dos resíduos sólidos;

4. de que modo difundir práticas exitosas que contribuam com as políticas locais e regionais.

A Conferência foi estruturada em quatro eixos temáticos: Produção e Consumo Sustentáveis; Redução dos Impactos Ambientais; Geração de Emprego, Trabalho e Renda; e Educação Ambiental. Sua discussão foi definida como de competência da Coordenação Executiva Regional, composta por representantes do Grupo de Trabalho, do Meio Ambiente e da Assessoria Técnica para apoio à execução das atividades. Foi proposta a criação de um Fórum Permanente, objetivando o acompanhamento e monitoramento dos resultados.

O município que apresenta um estágio mais avançado na gestão de resíduos sólidos é Santo André, cujo plano já foi elaborado e entregue: a Coleta de Resíduos Sólidos Perigosos foi implantada desde março de 2007, recebendo resíduos por meio de 16 estações espalhadas pelo município. A Coleta Seletiva de Resíduos Sólidos Comuns existe desde o ano de 1998. Parte do destino final desse lixo vai para o Aterro Sanitário de Mauá. Está prevista e em processo de licenciamento a ampliação do atual Aterro Sanitário para 2014, quando passará a receber todo lixo gerado e coletado no município.

A Tabela 6 apresenta dados sobre a situação de três municípios do ABC, Santo André, São Bernardo do Campo e São Caetano do Sul. 
Tabela 6: Situação dos municípios do Grande ABC em relação ao Plano Municipal de GRS

\begin{tabular}{|c|c|c|c|}
\hline & Santo André & S B Campo & S Caetano Sul \\
\hline $\begin{array}{l}\text { 1. O Plano Municipal foi elaborado/entregue? } \\
\text { 2. Existe coleta seletiva regular? }\end{array}$ & $\begin{array}{l}\text { Sim } \\
\text { Sim }\end{array}$ & $\begin{array}{l}\text { Em elaboração } \\
\text { Sim }\end{array}$ & $\begin{array}{l}\text { Sim } \\
\text { Sim }\end{array}$ \\
\hline $\begin{array}{l}\text { 3. Qual a frequência e abrangência da coleta } \\
\text { seletiva? }\end{array}$ & $\begin{array}{l}1 \text { vez por semana. } \\
\text { Todo o município }\end{array}$ & $\begin{array}{l}1 \text { vez por se- } \\
\text { mana. } \\
\text { Em ecopontos }\end{array}$ & $\begin{array}{l}1 \text { vez por se- } \\
\text { mana. Todos os } \\
\text { bairros }\end{array}$ \\
\hline $\begin{array}{l}\text { 3. Destinação final do lixo (aterro em processo } \\
\text { de construção) }\end{array}$ & $\begin{array}{l}\text { Sim. Em fase de } \\
\text { ampliação }\end{array}$ & $\begin{array}{l}\text { Projeto } \\
\text { concluído }\end{array}$ & Não \\
\hline 4. Previsão de construção de Aterro Sanitário & 2014 & 2015 & Não \\
\hline $\begin{array}{l}\text { 5. Existem cooperativas ou associações de cata- } \\
\text { dores de materiais recicláveis? }\end{array}$ & Sim & Sim & Não \\
\hline 6. O município participa dessa iniciativa? & Sim & Sim & Não \\
\hline $\begin{array}{l}\text { 7. Existem Projetos Educativos ou de Conscien- } \\
\text { tização da comunidade? }\end{array}$ & Sim & Sim & Sim \\
\hline 8. Existem outros projetos sobre o assunto? & Sim & Sim & Não informou \\
\hline
\end{tabular}

Fonte: dados de pesquisa coletados pelos autores.

Pelo exposto na Tabela 6, pode-se perceber que os municípios pesquisados elaboraram e entregaram seus respectivos PMGIRS, bem como procederam à implantação do processo de coleta seletiva, embora com estruturas diferenciadas. O município de Santo André, que já possui aterro sanitário, prevê a conclusão de suas ampliações para o ano de 2014, ao passo que o município de São Bernardo do Campo se encontra em fase de licenciamento do projeto (geração ou cogeração de energia a partir de incineração).

O município de São Caetano do Sul, por sua vez, não possui em seu território área útil que possa ser destinada à construção de aterro. Dessa forma, desenvolve parceria com municípios vizinhos para a destinação adequada dos seus resíduos. Importante destacar o fato de que todos os municípios pesquisados possuem projetos de educação/conscientização da comunidade com relação à geração, segregação e destinação correta dos resíduos. Somente o município de São Caetano do Sul declarou não possuir cooperativa ou associação de catadores de material reciclável. Complementando a informação transmitida pelos gestores locais, existem cooperativas na região, que atuam em mais de uma cidade, como a Cooperativa Central do $A B C$ (COOPCENT), região do ABC.

\section{CONCLUSÃO}

A contribuição deste trabalho foi mapear a situação dos municípios brasileiros e conferir a lacuna existente entre a emissão do diploma legal - resultante das políticas públicas que visam alinhar o Brasil aos acordos internacionais do quais ele foi estimulador e partícipe - e o atendimento dessa norma por parte das localidades, traduzidas em ações afirmativas. O Estado de São Paulo encontra-se em fase bastante adiantada em relação aos demais Estados da Federação, mas esse progresso não se traduz para todo o seu território, conforme pode ser observado na lista de 35 municípios em condições desfavoráveis, acrescentando-se a isso avanços e retrocessos. Quanto ao recorte regional, no ABC, o município de Santo André está na frente dos demais pesquisados. Os demais ainda não cumpriram totalmente as determinações legais, pois acreditam que esse prazo poderá ser dilatado (para 2015). 
O caminho percorrido neste estudo permite algumas constatações: o descolamento das políticas nacionais das realidades locais e regionais e a falta de uma política consistente de conscientização da população sobre cuidados e preservação do meio ambiente, que não ocorre por decreto ou campanhas genéricas e pontuais, mas por educação continuada.

Para atingir as metas propostas em curto prazo, é preciso que ocorra a destinação e liberação de recursos públicos e mobilização da sociedade. No entanto, foi perceptível o descompasso entre prazos de cumprimento das ações propostas e liberação de verbas. Já se observam movimentações de prefeituras no sentido de solicitar prorrogação deste prazo. No entender dos pesquisadores, tal pleito deverá ser aceito, uma vez que as ações públicas que visam ao cumprimento da Lei ainda estão em fase de assimilação social.

Finalmente, pode-se inferir que é preciso maior compreensão e firmeza na condução dos negócios públicos, condição indispensável para o sucesso de um empreendimento de interesse social, como o expresso no PNRS. No caso estudado, a região do $A B C$, verificou-se que os municípios pertencentes poderão ter atrasos na implementação plena do PNRS. Esta é uma bússola que permite fazer comparações com as demais regiões do país em seus distintos extratos de desenvolvimento. 
POLÍTICA NACIONAL DE RESÍDUOS SÓLIDOS: PERSPECTIVAS DE CUMPRIMENTO DA LEI 12.305/2010 NOS MUNICÍPIOS BRASILEIROS, MUNICÍPIOS PAULISTAS E MUNICÍPIOS DA REGIÃO DO ABC

\section{REFERÊNCIAS}

ABBAGNANO, N. Dicionário de Filosofia. São Paulo: Martins Fontes, 2000.

ASSOCIAÇÃO BRASILEIRA DE EMPRESAS DE LIMPEZA PÚBLICA E RESÍDUOS ESPECIAIS (ABRELPE). Resíduos sólidos: manual de boas práticas no planejamento. São Paulo, ABRELPE, 2013. Disponível em http:// www.abrelpe.org. br/arquivos/manual__ portugues_2013.pdf. Acesso em 18 jun 2013.

ANTUNES, P. B. Direito Ambiental, 12 ed. Rio de janeiro: Lumen Juris, 2010.

BAUDRILLARD, J. A Sociedade de consumo. Lisboa: Edições 70, 2000.

BRANCO, S. M. O Meio Ambiente em Debate. 26 ed. São Paulo: Moderna, 1997.

BRASIL. CONSTITUIÇÃO DA REPÚBLICA FEDERATIVA DO BRASIL, 1998.

BRASIL. INSTITUTO DE PESQUISA ECONÔMICA APLICADA. Plano Nacional de Resíduos Sólidos: diagnóstico dos resíduos urbanos, agrosilvopastoris e a questão dos catadores. Comunicados do Ipea, n. 145, IPEA, abr/2012. Disponível em http://www.ipea.gov.br. Acesso em 23 jul 2013.

BROWN, L. Nova York: Capital Mundial do Lixo. Worldwatch Institute. Washington: EPI, 2002.

CEMPRE - Compromisso Empresarial para Reciclagem. Radiografando a coleta seletiva. Pesquisa CEMPRE Ciclosoft 2012. Disponível em: <http://www.cempre.org.br/ ciclosoft_2012.php>. Acesso em: 17 jul. 2013.

CETESB - Companhia de Tecnologia de Saneamento Ambiental. Inventário Estadual de Resíduos Sólidos Urbanos. Secretaria Estadual do Meio Ambiente, 2012.

DALY, H. E. Ecological economics and the ecology of economics. New York: Edward Elgar, 1999.
DIÁRIO OFICIAL DA UNIÃO. Conferência das Nações Unidas sobre Meio Ambiente e Desenvolvimento. Agenda 21. Brasília, 02 Ago. 1994.

ESPINOZA, P.T.; E.M. ARCE; D. DAZA; M.S. FAURE; H. TERRAZA. AVAL - Relatório da Avaliação regional da gestão de resíduos sólidos urbanos na América Latina e Caribe 2010. AIDIS - Associación Interamericana de Ingeniería Sanitaria y Ambiental. São Paulo, 2011.

FISCHER,M. Futuros antropológicos. Rio de Janeiro: Zahar, 2011.

GIL, A. C. Como elaborar projetos de pesquisa. 5 ed. São Paulo, Atlas, 2010.

HOGAN, D. J.; MARANDOLA JR., E.; OJIMA, R. População e Ambiente: desafios à sustentabilidade. São Paulo: Blucher, 2010.

HOORNWEG, D.; BHADA-TATA, P. What a Waste: A Global Review of Solid Waste Management. Washington, World Bank, 2012.

HUISMAN, D. Dicionário de Obras Filosóficas. São Paulo: Martins Fontes, 2002.

INSTITUTO BRASILEIRO DE GEOGRAFIA E estatística, IBge/MUNIC, Perfil dos Municípios Brasileiros, 2011.

KLUNDERT, A. van de; ANSCHÜTZ, J. Integrated Sustainable Waste Management - the Concept: Tools for Decision-makers Experiences from the Urban Waste Expertise Program (1995-2001). Gouda, May 2001.

LÉLÉ, S. M. Sustainable development: a critical review. World Development, v. 19, n. 6, 1991.

MALTHUS T. R. Ensaio sobre a População. São Paulo: Nova Cultural, 1976.

MAVROPOULOS, A. Megacities Sustainable Development and Waste Management in the 21st Century, ISWA, 2010. Disponível

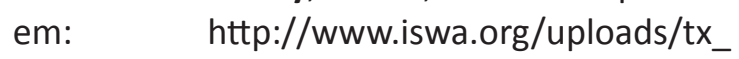
iswaknowledgebase/Mavropoulos.pdf. 
MILARÉ, E. Direito do Meio Ambiente. 5 ed. São Paulo: Revista dos tribunais, 2007

POLZIN, D. A. O. F. M. Gestão dos Resíduos sólidos Urbanos: Análise Comparativa entre Portugal e Brasil. Dissertação de Mestrado. Rio de Janeiro: Federal Fluminense Instituto de Geociência, 2004.

PORTILHO, F. Sustentabilidade Ambiental, Consumo e Cidadania. São Paulo: Cortez, 2005.

SEADON, J. K. Sustainable waste management systems. Journal of Cleaner Production, v. 18, n. 16-17, p. 1639-1651, 2010.

SECRETARIA MUNICIPAL DO MEIO AMBIENTE DO ESTADO DE SÃO PAULO/ Companhia de Saneamento Básico do Estado de São Paulo CETESB: Inventário Estadual de Resíduos Sólidos Urbanos, 2012.

UNEP - UNITED NATIONS ENVIRONMENT PROGRAMME. Waste Characterization and Qualification with Projections for Future. In: Developing Integrated Solid Waste Management Plan, Training Manual, v. 1, 2009.

UNITED STATES ENVIRONMENTAL PROTECTION AGENCY (EPA). Solid Waste Management: a local challenge with global impacts. Washington, D.C., May 2002.

VERGARA, S. C. Projetos e relatórios de pesquisa em Administração. 12 ed. São Paulo. Atlas, 2010. 
POLÍTICA NACIONAL DE RESÍDUOS SÓLIDOS: PERSPECTIVAS DE CUMPRIMENTO DA LEI 12.305/2010 NOS MUNICÍPIOS BRASILEIROS, MUNICÍPIOS PAULISTAS E MUNICÍPIOS DA REGIÃOO DO ABC

Rev. AdM. UfSM, SANTA MARIA, v. 7, EdIÇÃo EsPeCIAL, P. 93-110, NOV. 2014 - 110 - 